\title{
Homeopathy: a cured case
}

\begin{abstract}
The purpose of this article is to demonstrate the applications of a particular homeopathic remedy, Ignatia being applied by doctors and homeopaths universally. This is a case study of a young boy named Bhavesh More with HIV, renal artery stenosis and a high fever. The boy had difficulty speaking, elevated blood pressure, a lack of appetite and insomnia. The homeopathic remedy Ignatia $200 \mathrm{C}$ was given to the boy after repertorization analysis. Though he still has HIV, the major kidney symptoms and emotional shock from life traumas where remarkably reversed with the assistance of homeopathy.
\end{abstract}

Keywords: renal artery stenosis, appetite, HIV, blood pressure, ignatia
Volume I Issue 4 - 2015

\author{
Camille McClellan \\ Wellness and Nutrition, McClellan Natural Health, USA
}

Correspondence: Camille McClellan, Wellness and Nutrition, McClellan Natural Health, USA,

Email mcclellannaturalhealth@gmail.com

Received: May 23, 2015 | Published: August 31, 2015

\section{Introduction}

A young boy named Bhavesh More was diagnosed on April 1, 2009 with RAS (renal artery stenosis). He had a severe case of the disease which included high blood pressure and HIV. The child barely uttered a word when spoken to, had a poor appetite and a toxic build up in his body due to urine retention. His health slowly deteriorated as time progressed. He was placed on allopathic medication then a month later was admitted to a hospital with high fever.

His past medical history include a spiked fever and medications he was taking for RAS, HIV and high blood pressure. His family history included an HIV positive mother, sister and father who recently passed away. His physical exam reviled a lack of appetite, thirstlessness, no craving or aversions for particular foods, no bowel or urine complaints and he had trouble sleeping at night. The modalities included being a chilly person. ${ }^{1}$ The young boy, Bhavesh began to get extremely ill soon after his uncle died. This was a very traumatic incident for this young boy to experience at such a young age. The young boy evidently saw his uncle collapse and die, which sent him into immediate shock. Soon after this traumatic event he began to show sign of depression and withdrawal from life. It was said that due to his uncle and father's death Bhavesh was eventually diagnosed with renal artery stenosis. ${ }^{2}$

On examination within the hospital his pulse was 64, blood pressure 210/120 $\mathrm{mmHg}$, and temperature 99 degrees F. The medical diagnosis was RAS, hypertension and HIV and low hemoglobin. His lungs were clear however during the cardiovascular exam there were S1 and S2 sounds heard during auscultation. During the miasmatic analysis it was determined that he was syphilitic. According the practitioner that did the homeopathic consultation the child exhibited signs of sudden shock at the emotional and mental level. During this period Bhavesh experienced deterioration both physically, mentally and emotionally. He was apathetic, speechless and lacked a poor appetite.

At the mental level he showed sign of sensitivity and a lack of emotional feelings to anyone that displayed kindness though he was very affectionate and meek at times. As stated in the consultation the young child did see his uncle pass away which was such a traumatic event for him. Physically his body went into shock and soon after the event Bhavesh suffered right sided renal artery stenosis.
During the homeopathic consultation the young boys cried often and barely uttered a single word when spoken to. According to the doctor and author the homeopathic constitution depend on the nature of the person, their mental and emotional state and one's reaction to imminent situations. During the reportorial analysis the rubrics that were chosen were: right sided affection, aliments from shock or flight, sudden onset and conversation aggravate.

After the repertorization the remedies that were chosen were Alumina for its confused state, indecisiveness, peevish, hurried, confusion and a loss of memory. Natrium phosphoricum was chosen for problems with relationships, anxiety, fears, hyperactivity and withdrawing from others.

Phosphoricum acidum was a part of the rubric. It was chosen for anger, grief, sadness, indifference, homesickness, clairvoyance, mental weakness followed by physical weakness, over caring for others and thirst lessness. The last remedy that was chosen from the reportorial analysis was Ignatia. Some common symptoms of the remedy include grief after bad news, quickness, studious, desires to be alone, conscientious, competent, silent grief with control and inner sensitivity during disappointment.

Ignatia 200 given at one dose was the remedy of choice for this constitutional case. This is a plant remedy and was chosen for the sensations: shattered, shocked, torn to pieces, disappointment, ruined, shock which paralyzes. For passive reaction: sadness, cannot move, cannot weep, faint, silent and grief. Active reaction included convulsions, excitability and besides oneself .3 .

After the fifteen day follow up the young boy show improvement of his blood pressure to $170 / 100 \mathrm{mmHg}$. He also showed improvement in his appetite. On July 18th, 2009 he was later admitted to the hospital for convulsions. The remedy Ignatia one dose was repeated. On August 11th 2009 he had another follow up. He complained of a severe cough. On x-ray it revealed right sided pneumonia. Some rubrics added at this follow up were pain sore hold the chest, hands held chest, pain general lying aggravates. This time phosphorus was given to the child. The potency was 200 with one dose given that day.

After the follow up on August 28, 2009 the remedy seemed to improve many other symptoms. His blood pressure went to $110 / 10 \mathrm{mmHg}$, and his appetite increased. Bhavesh started smiling and communicating once again. He continued to show sensitivity to the world around him. Due to allopathic treatments for the HIV he began 
to have negative symptoms which sent him into the advance stages of its illness. The Ignatia did indeed assist with lowering the blood pressure. However, phosphorus certainly normalized the renal artery stenosis even further.

\section{Conclusion}

Bhavesh made improvements with Ignatia yet had set backs during the course of treatments due to the large volume of allopathic medications that were given to him during his stay at the hospital. However, phosphorus seemed to finally be the remedy that assisted in all his other problematic symptoms. Eventually, Bhavesh went on to make a complete recovery of all his complicated complaints.

\section{Acknowledgments}

None.

\section{Conflict of interest}

The authors declare that there is no conflict of interest.

\section{Funding}

None.

\section{References}

1. Morrison R. Desktop Guide: To Keynotes and Confirmatory Symptoms. Kandern, Germany: Hahnemann Clinic Publ; 1993. pp. 187-190.

2. Salunkhe A. Renal Artery Stenosis Cured. Homeopathy World Community. 2011.

3. Vermeulen F. Concordant Reference: Complete Classic Materia Medica. Belgium: B Jain Archibel; 2011. pp. 1014-1026. 